\title{
Medulloblastoma Treatment using Gene Therapy
}

\begin{abstract}
Usua lly initiated in cerebellum and the fourth ventricle and caused by the secondary increased intracranial pressure due to blockage of the fourth ventricle, medulloblastoma (MB) is the most common malignant brain tumor in children. Traditionally, surgical therapy is predominantly conducted with maximal resection of the tumor and followed by radiation or chemotherapy according to its philological subtypes. However, due to the fact that the traditional treatments result in unsatisfactory peripheral prognosis and the final death from relapse to most of the patients, increasing efforts have been made in the field of gene therapy to improve the prognosis. So far, four of gene therapy strategies have been tested in cells or a nimal xenograft models including 1 ) oncolytic virotherapy using adenovinus, reovinus, myxoma virus, and measles virus; 2) suicide gene therapy, focusing on HSV-tk with GCV system and rCE with CPT-11 system; 3) radiation sensitivity enhancement by down regulation of MMP-9, UPAR, SPARC CDK6 or elevation of NIS; and 4) miRNA-based gene therapy. To date, gene therapy to MB has been proven to be promising at the level of cells lines and xenograft mouse models although no clinic al tria ls have been conducted. In this paper, we review the relevant gene therapy strategies for the MB treatments and disc uss the pertinent challenges, further refinement and future directions in this field.
\end{abstract}

\section{Instruction}

As a primary malignant embryonal tumor of the central nervous system (CNS) arising infratentorially in the cerebellum or fourth ventricle, medulloblastoma $(\mathrm{MB})$ accounts for $12-25 \%$ and is believed to be one of the most common childhood CNS tumors [1]. Based on the World Health Organization classification, five different histologic variants have been acknowledged: classic MB (CMB), desmoplastic/nodular $\mathrm{MB}$ (DMB), $\mathrm{MB}$ with extensive nodularity (MBEN), large-cell MB (LC MB) and anaplastic MB (AMB) [2]. Assessed histopathologically and neuroradiologically, the optimal risk stratification is made for traditional treatments: a maximal safe surgery, followed or not by craniospinal radiotherapy and chemotherapy [3]. Although the progress has been made by optimizing the treatment techniques, leading to $50 \%$ to $80 \%$ of the 5 -year survival rate in children patients $[4,5]$, development of the new therapeutic strategies like gene therapy are indispensable to improve the prognosis and to reduce the side effects brought about by traditional treatments. Gene therapy is defined as the treatment of certain disorders caused by genetic anomalies or deficiencies through introducing specifically engineered genes into a patient's cells or by other genetic engineering strategies to replace or correct the alteration of specific genes. To date, gene therapy has yielded encouraging results clinically in several diseases such as Leber's congenital amaurosis (LCA), X-linked severe combined immunodeficiency (X-linked SCID), Adenosine deaminase deficiency(ADA-SCID), adrenoleukodystrophy, chronic lymphocytic leukemia (CLL), acute lymphocytic leukemia (ALL), multiple myeloma and Parkinson's disease [6-13]. By contrast, the gene therapy - based treatment for $\mathrm{MB}$ is only at the levels of cell lines and preclinical animal models not yet at clinic stage, however, it is considered as a very new promising strategy to complement

\section{Journal of} Gene Therapy

\author{
Jian Li ${ }^{1,2,3}$, Xianrui Yuan ${ }^{1}$, Jingping Liu ${ }^{1,2}$ and \\ Yujing $\mathrm{Li}^{3 *}$ \\ ${ }^{1}$ Department of Neurosurgery, Xiangya Hospital, Central South \\ University, Institute of Skull Base Surgery and Neurooncology at \\ Hunan, 87 Xiangya Road, Changsha, Hunan 410008, China \\ ${ }^{2}$ Hydrocephalus center, Xiangya Hospital, Central South University, \\ 87 Xiangya Road, Changsha, Hunan 410008, China \\ ${ }^{3}$ Department of Human Genetics Emory University School of \\ Medicine 615 Michael St. Atlanta, GA 30322, USA
}

\section{Address for Correspondence}

Dr. Yujing Li, Department of Human Genetics, Emory University School of Medicine, 615 Michael, St Atlanta, GA, USA 30322, Tel: (678)-2217358; E-mail: yli29@emory.edu

Dr. Jingping Liu, Department of Neurosurgery, Xiangya Hospital, Central South University, Institute of Skull Base Surgery and Neurooncology at Hunan, 87 Xiangya Road, Changsha, Hunan 410008, China, Hydrocephalus center, Xiangya Hospital, Central South University, 87 Xiangya Road, Changsha, Hunan 410008, China. Tel: 86-139-08465779; E-mail: liujp5779@163.com

Copyright: @ $2013 \mathrm{Li} \mathrm{J}$, et al. This is an open access article distributed under the Creative Commons Attribution License, which permits unrestricted use, distribution, and reproduction in any medium, provided the original work is properly cited.

Submission: 20 July 2013

Accepted: 29 July 2013

Published: 04 September 2013

the traditionally surgery-based therapy. The most widely used anti$\mathrm{MB}$ gene therapy strategies include: 1) oncolytic virotherapy, 2) suicide gene therapy, 3) radiation sensitivity enhancement, and 4) miRNA-based gene therapy. Here, we summarize the relevant gene therapy approaches for the MB treatment and discuss the pertinent shortcomings, further refinement and future directions in this field.

\section{Oncolytic Virotherapy}

Oncolytic virotherapy $(\mathrm{OV})$ is an emerging treatment modality that utilizes viruses to preferentially infect and self-replicate in tumor cells, leading to tumor cell lysis [14]. The development of virotherapeutic strategy has evolved from the use of in vitro-passaged strains (first generation), to genetically engineered selectivityenhanced viruses (second generation) and finally to genetically engineered transgene-expressing 'armed' oncolytic viruses (third generation) [15]. Targeting specificity of virus to cancer cells is essential. Some viruses, such as the $\mathrm{H} 1$ autonomously replicating parvovirus, retrovirus, Newcastle disease virus, mumps virus and Moloney leukemia virus, have a natural preference for cancer cells, whereas viruses such as measles, adenovirus, vesicular stomatitis virus (VSV), vaccinia and herpes simplex virus (HSV) can be adapted or engineered to make them cancer specific. The OVs have been performed in many kinds of tumors, such as glioma, lung cancer, pancreatic cancer, gastrointestinal cancer, breast cancer [14]. Here, we briefly introduce some of the most commonly used anti-MB OV systems.

\section{Adenovirus}

A mutant adenovirus, Delta-24, which has a 24-base pair deletion in the Rb-binding region of the E1A gene, demonstrates selective replication and oncolysis in two MB cell lines. Replication-deficient adenovirus to transduce showed that the Delta-24 adenovirus infects 
99\% of Daoy and 46\% of D283 Med medulloblastoma cells at a multiplicity of infection (MOI) of 50. A total cytopathic effect in Daoy and D283 Med medulloblastoma cells after 6 and 8 days of infection, respectively. Infectivity assays showed cell death correlated with the accumulation of cells in the $S$ phase. The release of viral progeny was quantified as being increased by two orders of magnitude, indicating efficient replication of Delta-24 in medulloblastoma cells [16].

\section{Reovirus (RV)}

$\mathrm{RV}$ is a double-stranded RNA binding to mammalian cells through ubiquitous sialic acid and junction adhesion molecule and preferentially infects and lyses tumor cells but not normal cells by usurping the activated Ras-signaling pathway for replication [17] Human reovirus type 3 can target most human $\mathrm{MB}$ cell lines tested (five of seven $=71.4 \%$ ), two $\mathrm{MB}$ cell lines derived from spontaneously arising tumors in Patched-1(+/-) mice (two of two $=100 \%$ ) and three MB primary cultures derived from surgical specimens. RV was internalized and transcribed in both susceptible and resistant cell lines. However, viral protein synthesis was restricted to cell lines with higher levels of activated Ras, suggesting that Ras plays a critical role in reovirus oncolysis in $\mathrm{MB}$ [18].

\section{Myxoma Virus (MYV)}

MYV is a rabbit-specific poxvirus pathogen that also exhibits a unique tropism for human tumor cells and is dramatically oncolytic for human cancer xenografts [19]. MYV-based anti-MB OV was initially used in experimental MB models both in vitro and in vivo due to its advantages of efficiency and safety, and what is more, the effect coffered by MYV can be enhanced by combining with rapamycin which modulates activity of the phosphatidylinositol 3-kinase/Akt pathway [20].

\section{Measles Virus (MV)}

As one of the most widely used for OV-mediated eradication of brain tumors, MV has extensively been tested in all the five available $\mathrm{MB}$ cell lines, MB tissue specimen and the murine xenograft model. In all the tested MB cells, once infected with MV-GFP, the MB cells usually form syncytia and then are dramatically killed. In an intracerebral murine xenograft model, compared to inactivated MV, the active MV treatment leads to significantly higher survival rate [21]. Besides the effectiveness in the intracerebral murine xenograft model, the MV treatment has been proven to be effective in the murine ventricle xenograft model as well [12]. When mice injected with $\mathrm{MB}$ cells into their right lateral ventricle, tumors grow in their ventricles and in both intracranial and spinal subarachnoid spaces. However, the subsequent intraventricular administration of MV results in stabilization and shrinkage of the tumors, significantly prolonging the survival of the treated animals and demonstrating the significant curing effect conferred by the oncolytic MV in cerebral spinal fluid-disseminated MB [22].

\section{Suicide Gene Therapy}

Suicide gene therapy has been proposed with mechanism that viral vectors or cell carriers are genetically modified to express an enzyme that is able to convert an inactive prodrug into toxic metabolites at the tumor sites, resulting in tumor cell killing specifically [23]. Herpes simplex virus thymidine kinase (HSV-tk) with ganciclovir (GCV) is the most extensively applied system in which the inactive prodrug ganciclovir (GCV) is converted into a toxic metabolite called GCV- triphosphate by HSV-tk [24]. Neural stem cells (NSCs) can effectively cross the blood-brain barrier and selectively target anti-cancer agents to invasive tumor cells, local drug concentrations and the therapeutic index can be increased while minimizing toxicity to normal tissues [25]. As a result, NSCs is widely used in the treatment of brain tumor.

A successful example is NSCs line C17.2-mediated suicide gene therapy in a way that C17.2 is applied as the carrier and transduced with the HSV-tk gene to generate C17.2-tk cells [15]. Then the C17.2tk cells are mixed with human MB cell line Daoy at various ratios and supplemented with GCV both in vitro and in vivo, and the significant cell killing is induced even at a ratio of C17.2-tk: Daoy $=$ 1:16 (still more than $25 \%$ cell killing in vitro). Under the condition of in vivo co-implantation with the C17.2-tk: Daoy ratio $=1: 8$, tumor growth inhibition is significant, leading to prolonged survival for the xenografted model mice [26].

Another most extensively utilized suicide gene system is rabbit carboxylesterase (rCE) with camptothecin-11 (CPT-11) (Irinotecan) in which prodrug CPT-11 is converted to potent topoisomerase I inhibitor SN-38 [27]. The iron nanoparticle-labeled and genetically modified human NSC line (HB1.F3.CD) which carries rCE was used to target the cerebellar tumor foci to activate the prodrug CPT-11 locally. Due to the magnetic property of iron nanoparticles, tumor dynamic growth in vivo could be easily detected by magnetic resonance imaging (MRI) tracking. In this case, the MRI shows significant decrease in tumor growth rate in mice that received both NSCs and CPT-11 as their treatment regimen [28].

\section{Radiation Sensitivity Enhancement}

Non-operative management with roentgen therapy after aspiration biopsy, later on known as "radiotherapy" was reported initially in 1949 [29]. Since then, the ever-lasting efforts have been made in radiotherapy for both basic biomedical research and clinical practice for MB treatment, and the effect of radiotherapy is convinced. Ionizing radiation acts through the induction of double-strand DNA breakage to eliminate cancerous cells via apoptosis [30]. To date, radiotherapy remains the main modality in the curative treatment of $\mathrm{MB}$ patients. However, shortcomings of the radiotherapy itself strongly limits its contribution to cancer therapy, which include the low efficacy and severe side effects such as: 1) neurocognitive defect [31] especially for pediatric patients, 2) no discrimination between normal and cancer cells, resulting large scale of normal cells death or induced secondary tumors such as brain, rectal, breast, lung, stomach, and thyroid cancer, and 3) heart failure [32]. In addition, cancer cells often develop radio-resistance mechanisms that are related to the DNA repair response [33]. To overcome these deadly disadvantages, it is essential to develop new accessory strategies that could reduce the dose of radiation and sensitize the MB cells to radiotherapy.

So far almost all the strategies developed to enhance the radiotherapeutic efficiency are involved in modification of cell cycle (Table 1). Of the strategies that have been developed, altering expression of Matrix metalloproteinase-9 (MMP-9) and urokinase plasminogen activator receptor ( $\mathrm{UPAR}$ ) takes the pilot step. The MMP-9 and UPAR are highly expressed in several types of cancers and considerable evidences show that radiation elevates UPAR and MMP9 expression in MB cells. siRNA-mediated knockdown of uPAR and MMP-9, either alone or in combination with radiation modulates a series of events including G2/M cell-cycle arrest in MB [34] and inactivation of EGFR/STAT3 signaling pathway, leading to apoptosis 
Table 1: Oncolytic Virotherapy.

\begin{tabular}{|c|c|c|}
\hline \multicolumn{1}{|c|}{ Virus } & Character & Cell Line Or Model \\
\hline Adenovirus & $\begin{array}{c}\text { Target coxsackie adenovirus receptor and } \\
\text { RGD-related integrins. } \\
\text { Replication competent. }\end{array}$ & Daoy and D283 cell lines. \\
\hline Reovirus & $\begin{array}{c}\text { Target tumors with high level of activated } \\
\text { Ras signal. } \\
\text { Replication competent. }\end{array}$ & $\begin{array}{c}\text { Daoy, D283, U87, U118, D341, D425, D384, SJMM1 } \\
\text { and SJMM2, ONS-76 MB cell lines and three biopsy } \\
\text { samples of human MB. } \\
\text { Daoy xenograft mouse model. }\end{array}$ \\
\hline Myxoma virus & $\begin{array}{c}\text { Target tumor cell specifically. Replication } \\
\text { competent. }\end{array}$ & $\begin{array}{c}\text { Daoy, UW228, TE671, D283, D341, D425, D384, } \\
\text { Ptc850, Ptc1102 and ONS76 MB cell lines. } \\
\text { D341, Daoy xenograft mouse model. }\end{array}$ \\
\hline Measles virus & Recognize CD46, over-expressed in \\
tumors. & $\begin{array}{c}\text { Daoy, D283, D341, UW288-1 and UW426 cell lines. } \\
\text { D283 localized and D283, D245 disseminated } \\
\text { xenograft mouse models. }\end{array}$ \\
\hline
\end{tabular}

[35]. Thus, RNAi-mediated knock down of uPAR and MMP-9 in combination with radiotherapy might become a promising strategy for MB treatment.

Similarly, alteration of the secreted protein acidic and rich in cysteine (SPARC) could dramatically enhance the radiotherapeutic response in MB cells as well. The SPARC is a matricellular glycoprotein and a putative radioresistance-reversal-gene, participating in the regulation of morphogenesis and cellular differentiation through its modulation of cell-matrix interactions. By inducing cell cycle arrest via STAT3 and Notch signaling pathways, SPARC overexpression significantly impairs $\mathrm{MB}$ tumor growth in vitro and in vivo $[36,37]$ in a way that overexpressed SPARC prior to irradiation suppresses checkpoints-1, -2, p53 phosphorylation, and the expression of the DNA repair gene XRCC1. Another mechanism is suppression of the irradiation induced and SOX-4 mediated DNA repair under conditions of SPARC overexpression [38].

Alternatively, cell cycle modification-based radiotherapy enhancement could be conducted by inhibiting the enzyme activity or interfering with expression of cyclin-dependent kinase 6 (CDK6) which expresses at significantly higher levels in MB patient compared to that in normal control people. Experimentally, siRNA mediated knock down or kinase activity inhibition with a small molecule inhibitor PD0332991 could efficiently suppress the MB cell proliferation due to a G0/G1 cell cycle arrest, leading to loss of colony forming potential. Thus, pretreatment with PD0332991 could make the MB cells more sensitive to ionizing radiation [39].

In addition to cell cycle modification, enhancement of the radiotherapy efficiency can be alternatively achieved as well by delivering the targeted radiotherapy to the tumor site and promoting a localized bystander effect. Human thyroidal sodium iodide symporter (NIS) bears this function once it is overexpressed into measles virus and introduced to mouse xenograft models, evidenced by the fact that the overexpression of NIS significantly increases the survival rate for both in localized and disseminated MB athymic nude mice xenograft models given a dose of I131 [40].

\section{microRNA (miRNA) - based Gene Therapy}

microRNAs are a group of small non-coding RNA molecules with approximately 22 nucleotides, and have been acknowledged as one of the most important mechanisms for gene expression at posttranscriptional level in plants and animals [41]. miRNAs function via base-pairing with complementary sequences within mRNA molecules, usually resulting in gene silencing via translational repression or target mRNA degradation, controlling the diverse biological pathways relating to chromosome architecture and segregation behavior, transcription, and RNA processing and stability, and thereby to phenotypically coordinate development, growth control, apoptosis, self defense, and stem cell maintenance [42]. This novel class of molecules modulates a wide array of growth and differentiation processes in human cancers. As consistent with the natural function of miRNAs in specifying cellular phenotype, miRNA-based cancer gene therapy offers theoretical appeal of targeting multiple gene networks that are controlled by a single, aberrantly expressed miRNA. Reconstitution of tumor-suppressive miRNA, or sequence-specific knockdown of oncogenic miRNAs by 'antagomirs,' has produced favorable antitumor outcomes in experimental models $[43,44]$.

Starting from identification of miR124a that targets CDK6 and shows expression deficiency in $\mathrm{MB}$ [45], more than 30 aberrant expressed miRNAs have been profiled in $\mathrm{MB}$, some under-expressed such as miR-124, miR-199b-5p, miR-125b, miR-324-5p, miR-326, miR128, miR-139, miR-let7g, miR383 and some over-expressed such as miR17-5p, [46-50].

Due to deficiency of miR124a level in MB, level of its target CDK6 which is identified as an adverse prognostic marker is accordingly elevated in some MB. Similarly, Solute carrier family 16 (SLC6), another target of miR124 that functions to efflux lactic acid during aerobic glycolysis is over-expressed as well in MB. Transfection-based overexpression of miR124 significantly decreases MB cell growth but does not alter apoptosis $[45,51]$. Further engineering consolidates the tumor repression by infection of lenti-virus expressing miR-124 to inhibit growth of MB xenograft tumors in mice [47]. Functional study on other more than 30 of the aberrant expressed miRNAs has been carried out and therapeutic effects in vitro or in vivo with the tactics of reversing the expression level of these miRNAs have proven to be promising (Table 2).

miRNAs-mediated inhibition of $\mathrm{MB}$ cell proliferation and $\mathrm{MB}$ metastasis by targeting the Notch signaling pathway have been tested in xenograft model. Since the Notch signaling pathway regulates a subset of $\mathrm{MB}$ cells to enhance the stem-cell-like properties and promotes tumor growth, miRNAs such as miR199b-5p and miR34a that target the Notch signaling pathway may be engineered for MB therapy $[48,52]$. It has been shown that miR199b-5p level is significantly higher in non-metastatic $\mathrm{MB}$ cases than in metastatic cases, suggesting miR199b-5p conferred inhibition of MB metastasis. Further experiment shows that miR199b-5p can target Notch effector: HES1, which prevents both migration of neural progenitor cells out of the ventricular zone and expression of neuronal markers 
Table 2: Radiation Sensitivity Enhancement Therapy.

\begin{tabular}{|c|c|c|c|}
\hline Methods & Function & Cell line or model & Reference \\
\hline $\begin{array}{l}\text { siRNA vectors transfection with FuGENE } \\
\text { HD }\end{array}$ & silence UPAR, MMP-9 & Daoy, D283 MB cell lines. & [34] \\
\hline $\begin{array}{c}\text { pcDNA3.1 vector transfection with FuGene } \\
\text { HD }\end{array}$ & over express SPARC & $\begin{array}{l}\text { D425, UW228, H2411MB cell lines. } \\
\text { D425 xenograft mouse model. }\end{array}$ & [38] \\
\hline PD0332991 treatment & silence cyclin-dependent kinase 6 (CDK6) & Daoy, ONS-76 MB cell lines. & [39] \\
\hline $\begin{array}{l}\text { NIS encoded Myxoma virus, Administration } \\
\text { of } 131 \text { I }\end{array}$ & $\begin{array}{l}\text { concentrate radioiodine at the site of tumor } \\
\text { implantations }\end{array}$ & $\begin{array}{c}\text { D283, UW426 MB cell lines. } \\
\text { Localized and disseminated mouse models. }\end{array}$ & {$[40]$} \\
\hline
\end{tabular}

Table 3: RNA interference (RNAi) - based gene therapy.

\begin{tabular}{|c|c|c|c|c|}
\hline microRNAs & Methods & Targets & Cell line or model & Reference \\
\hline $\operatorname{miR} 124$ & lentivirus & $\begin{array}{c}\text { cyclin-dependent kinase } 6 \text { (CDK6), } \\
\text { Solute carrier family } 16 \text { member } 1 \\
\text { (SLC16A1) }\end{array}$ & $\begin{array}{l}\text { D283, D341, D384, D425, D458, ONS-76 MB } \\
\text { cell lines. D425 xenograft tumors in mice. }\end{array}$ & {$[45,51]$} \\
\hline miR199b-5p & adenovirus & $\begin{array}{l}\text { transcription factor HES1 } \\
\text { MB stem-cell-like (CD133+) } \\
\text { subpopulation of cells }\end{array}$ & $\begin{array}{l}\text { Daoy cell line and } \\
\text { Daoy xanograft mouse model. }\end{array}$ & [48] \\
\hline miR34a & adenovirus & Notch ligand Delta-like 1 (DII1) & $\begin{array}{c}\text { Daoy cell line and } \\
\text { Daoy xanograft mouse model. }\end{array}$ & {$[52]$} \\
\hline $\begin{array}{l}\text { miR125b, miR324- } \\
\quad 5 p, \text { miR326 }\end{array}$ & $\begin{array}{l}\text { DharmaFECT-2 transfection } \\
\text { reagent } \\
\text { Lipofectamine Plus }\end{array}$ & Smoothened (Smo), Gil & Daoy and D283 cell lines. & [49] \\
\hline $\operatorname{miR} 128 a$ & Lipofectamine 2000 & Bmi-1 & Daoy, ONS-76 cell lines. & {$[46]$} \\
\hline miR383 & Lipofectamine 2000 & Peroxiredoxin 3 (PRDX3) & $\begin{array}{l}\text { Daoy, D283, D341, D384, D425, D458, ONS- } \\
76 \text { cell lines. }\end{array}$ & {$[50]$} \\
\hline miR9, miR125a & Lipofectamine 2000 & $\mathrm{t}-\mathrm{TrkC}$ & D283 and Daoy cell lines. & {$[55]$} \\
\hline
\end{tabular}

[53]. Over-expression of miR199b-5p reduces cell proliferation and impairs the clonogenic potential of $\mathrm{MB}$ cell lines. $\mathrm{MB}$ tumor infection by adenovirus carrying miR199b-5p in a xenograft model significantly reduces the tumor burden, indicating the possibility that the use of miR199b-5p as an adjuvant therapy after surgery to control its metastasis [48]. miR-34a is believed to be a regulator of the Notch signaling pathway through targeting on Notch ligand Delta-like 1 (Dll1). Down-regulation of Dll1 expression by miR-34a negatively regulates cell proliferation, and induces apoptosis and neural differentiation in $\mathrm{MB}$ cells. Infection of adenoviruses carrying the precursor miR-34a induces neurogenesis of tumor spheres and reduces tumor burden in cerebellum xenografts of athymic mice, demonstrating an anti-tumorigenic role of miR-34a in vivo [52] Interestingly, miR-34a is able to confer chemosensitivity as well through directly targeting the 3' UTRs of MAGE-A genes, reducing MAGE-A and increasing p53 in MB [54].

Besides the miRNAs as summarized above whose MB suppressing effects have been confirmed both in vitro and in vivo, a group of miRNAs tested only in MB cells but not in vivo have been proved to be MB inhibitors as well such as miR125b, miR324-5p and miR326, miR-128a, miR383, miR9, miR-125a and miR218, or to be enhancers such as miR 17-92 [46,49,50,55,56]

Of the identified aberrant miRNAs, miR125b, miR324-5p and miR326 belong to a group of down-expressed miRNAs in MB, they suppress Hedgehog $(\mathrm{Hh})$ signaling which controls cerebellar granule cell progenitor (GCP) development by targeting 3'UTR of Smoothened (Smo) and transcription factor Gil functioning as downstream effectors of Hh signaling pathway. Subversion of this pathway leads to neoplastic transformation into $\mathrm{MB}$ [57]. Overexpression of these miRNA not only increases cerebellar GCP differentiation, but also significantly inhibits Daoy MB cell proliferation, and thereby reduces the size and number of Daoy MB cell colonies [49].

Some other miRNAs such as miR-128a, miR-383, miR-9, miR$125 \mathrm{a}$ and miR-218, are believed to be MB suppressors as well in a way that either directly inhibit MB cell growth, proliferation or by promoting $\mathrm{MB}$ cell senescence by targeting different signaling pathways. For example, by targeting the Bmi-1 oncogene, miR-128a inhibits growth of MB cells and alters the intracellular redox state of the tumor cells and thereby promotes cellular senescence [46], while miR-383 is down-regulated in $\mathrm{MB}$ and overexpression of miR383 inhibits MB cell growth through targeting peroxiredoxin 3 (PRDX3) [50]. Similarly, miR-9 and miR-125a, their rescued expression promotes $\mathrm{MB}$ cell growth arrest and apoptosis while targeting the proliferative truncated TrkC isoform [55]. miR-218 is known as a tumor suppressor by targeting multiple cancer phenotype-associated genes such as REST, CDK6, RICTOR and CTSB (cathepsin B) in MB [26].

\section{Concluding Remark}

Compared with clinical application status of gene therapy to other tumors like glioma, gene therapy in $\mathrm{MB}$ is still at the preclinical stage (Figure 1), long way to go before the effective regimen of gene therapy is found and tested clinically on patients. Promisingly, most of the gene therapy strategies including oncolytic virotherapy, suicide gene therapy, radiation sensitivity enhancement and miRNA-based gene therapy, have been performed successfully in cells or animal models with very much encouraging therapeutic effects. The next step of gene therapy in $\mathrm{MB}$ is to extend one method or combined methods in vitro and in vivo into clinical trials, and to that end, some major obstacles remain to be overcome prior to clinical trials such as the specificity 


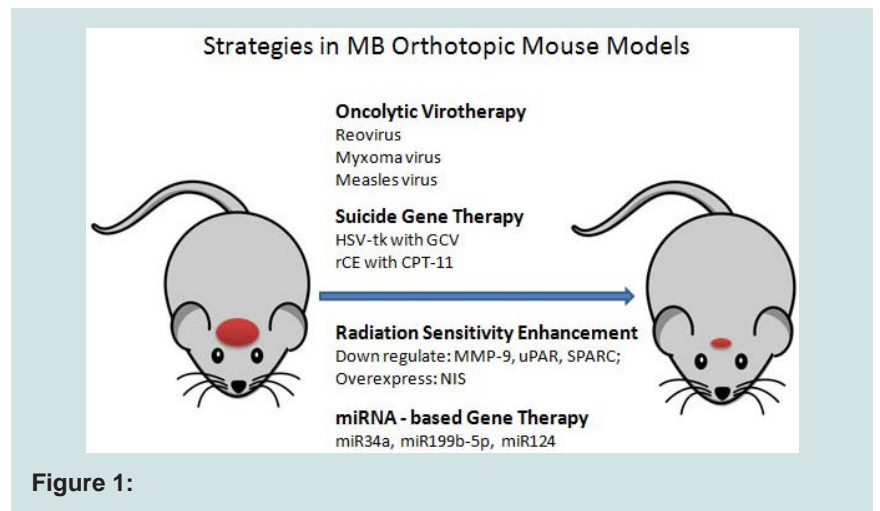

of the target tumor cells to reduce the risks incurred by non-specific infection of virus and enhanced intratumoural distribution.

For virus-mediated gene therapy to treat cancer, infection specificity of the virus to cancer cells instead of normal tissues is one of the key considerations. So far the viruses tested for MB therapy none of them specifically infects host cancer cells even the most widely used viruses such as oncolytic virus, vaccine strain Measles virus and Myxoma virus which are trusted to have a remarkable safety record for treatment of myeloma, ovarian carcinoma, glioma $[21,58]$. Modified adeno-virus and lenti-virus are used to deliver the vectors that harbor miRNA precursors for RNA interference, while usually they are replication incompetent, these viruses still infect the normal tissues around the tumor. Thus, it is essential that guarantee the specificity of the virus infection to MB cells instead of normal neuron or gliocyte when extend the virus-mediated gene therapy from cells and animal models to clinical trials.

Currently, all the xenograft models except those in oncolytic virotherapy are constructed by virus infected MB cells, making sure that the efficacy is high enough for the phenotype. However, the difference exists between the xenograft models and human MB patient due to the blood-brain barrier that decrease the spatial distribution of the administered therapy like in other brain tumors. Thus, most antiglioma gene therapeutic approaches are applied during craniotomy directly in the tumor bed or into the margins of the tumor cavity itself. Despite direct delivery, the transduction efficiency of glioma cells with the currently available viral and nonviral vectors remains poor [23]. In the terms of oncolytic virotherapy, not all the cells lines showed the same level of vulnerability. Some cell lines have week replication like D283 cell lines for adenovirus [16] or low level of virus targets like D341 and D384 cell lines for reovirus [18].

To improve the specificity and the transduction efficiency, MB should be studied well for the molecular subdivision and optimized tactics should be chosen individually. Some new techniques might be needed to considered, like nanoparticle technique. Nanoparticles have been extensively applied for the carriers to bring the drugs or plasmids harboring the expression vectors, or miRNA, siRNA and so on into the tumors for therapeutic purpose. As the successful examples for nanoparticle-mediated MB therapy, Curcumin, HPI-1, and Impramine blue (IB) have been encapsulated by different polymer nanoparticles into NanoHHI, Liposome-IB, and NanoCurc then introduced to $\mathrm{MB}$ cell lines and mice model through intraperitoneal or tail vein injection and show therapeutic effect [29-61]. Although currently application of the nanoparticles on MB treatment is only on the stage of cell lines or mouse model, the enhanced permeability, systemic delivery and retention effect that this technique brought about shed light on the future therapeutic perspective on the MB treatment [28]. Although the study in gene therapy-based MB treatment is challenging, it is highly expected that significant improvement on gene therapy techniques will be a big addition to the conventional MB treatments.

\section{References}

1. Bartlett F, Kortmann R, Saran F (2013) Medulloblastoma. Clin Oncol (R Coll Radiol) $25: 36-45$.

2. Louis DN, Ohgaki H, Wiestler OD, Cavenee WK, Burger PC, et al. (2007) The 2007 WHO classification of tumours of the central nervous system. Acta Neuropathol 114: 97-109.

3. von Hoff K, Rutkowski S (2012) Medulloblastoma. Curr Treat Options Neurol 14: 416-26.

4. McNeil DE, Coté TR, Clegg L, Rorke LB, et al. (2002) Incidence and trends in pediatric malignancies medulloblastoma/primitive neuroectodermal tumor: a SEER update. Surveillance Epidemiology and End Results. Med Pediatr Oncol 39: 190-194.

5. Packer RJ (2005) Progress and challenges in childhood brain tumors. J Neurooncol 75: 239-42.

6. Simonelli F, Maguire AM, Testa F, Pierce EA, Mingozzi F, et al. (2010) Gene therapy for Leber's congenital amaurosis is safe and effective through 1.5 years after vector administration. Mol Ther 18: 643-50.

7. Fischer A, Hacein-Bey-Abina S, Cavazzana-Calvo M (2010) 20 years of gene therapy for SCID. Nat Immunol 11: 457-460.

8. Ferrua F, Brigida I, Aiuti A (2010) Update on gene therapy for adenosine deaminase-deficient severe combined immunodeficiency. Curr Opin Allergy Clin Immunol 10: 551-556.

9. Cartier N, Aubourg P (2010) Hematopoietic stem cell transplantation and hematopoietic stem cell gene therapy in X-linked adrenoleukodystrophy. Brain Pathol 20: 857-62.

10. Ledford H (2011) Cell therapy fights leukaemia. Nature.

11. Coghlan A (2013) Gene therapy cures leukaemia in eight days. The New Scientist 217: 10

12. Coghlan A (2012) Souped-up immune cells force leukaemia into remission. New Scientist 216: 17.

13. LeWitt PA, Rezai AR, Leehey MA, Ojemann SG, Flaherty AW, et al. (2011) AAV2-GAD gene therapy for advanced Parkinson's disease: a double-blind, sham-surgery controlled, randomised trial. Lancet Neurol 10: 309-319.

14. Russell SJ, Peng KW, Bell JC (2012) Oncolytic virotherapy. Nat Biotechnol 30: 658-670.

15. Liu TC, Galanis E, Kirn D (2007) Clinical trial results with oncolytic virotherapy: a century of promise, a decade of progress. Nat Clin Pract Oncol 4: 101-117.

16. Stolarek R, Gomez-Manzano C, Jiang H, Suttle G, Lemoine MG, et al. (2004) Robust infectivity and replication of Delta-24 adenovirus induce cell death in human medulloblastoma. Cancer Gene Ther 11: 713-720.

17. Coffey MC, Strong JE, Forsyth PA, Lee PW (1998) Reovirus therapy of tumors with activated Ras pathway. Science 282: 1332-1334.

18. Yang WQ, Senger D, Muzik H, Shi ZQ, Johnson D, et al. (2003) Reovirus prolongs survival and reduces the frequency of spinal and leptomeningeal metastases from medulloblastoma. Cancer Res 63: 3162-72.

19. Stanford MM, Barrett JW, Nazarian SH, Werden S, McFadden G, et al. (2007) Oncolytic virotherapy synergism with signaling inhibitors: Rapamycin increases myxoma virus tropism for human tumor cells. J Virol 81: 1251-60.

20. Lun XQ, Zhou H, Alain T, Sun B, Wang L, et al. (2007) Targeting human medulloblastoma: oncolytic virotherapy with myxoma virus is enhanced by rapamycin. Cancer Res 67: 8818-27. 
21. Studebaker AW, Kreofsky CR, Pierson CR, Russell SJ, Galanis E, et al (2010) Treatment of medulloblastoma with a modified measles virus. Neuro Oncol 12: 1034-42

22. Studebaker AW, Hutzen B, Pierson CR, Russell SJ, Galanis E, et al. (2012) Oncolytic measles virus prolongs survival in a murine model of cerebral spinal fluid-disseminated medulloblastoma. Neuro Oncol 14: 459-70.

23. Tobias A, Ahmed A, Moon KS, Lesniak MS (2013) The art of gene therapy for glioma: a review of the challenging road to the bedside. J Neurol Neurosurg Psychiatry 84: 213-22.

24. Gomez-Manzano C, Jiang H, Alonso M, Yung WK, Fueyo J (2012) Gene therapy. Handb Clin Neurol 104: 331-8.

25. Brown AB, Yang W, Schmidt NO, Carroll R, Leishear KK, et al. (2003) Intravascular delivery of neural stem cell lines to target intracranial and extracranial tumors of neural and non-neural origin. Hum Gene Ther 14 1777-85.

26. Pu K, Li SY, Gao Y, Ma L, Ma W, et al. (2011) Bystander effect in suicide gene therapy using immortalized neural stem cells transduced with herpes simplex virus thymidine kinase gene on medulloblastoma regression. Brain Res 1369: 245-52.

27. Danks MK, Yoon KJ, Bush RA, Remack JS, et al. (2007) Tumor-targeted enzyme/prodrug therapy mediates long-term disease-free survival of mice bearing disseminated neuroblastoma. Cancer Res 67: 22-25.

28. Gutova M, Shackleford GM, Khankaldyyan V, Herrmann KA, Shi XH, et al (2013) Neural stem cell-mediated CE/CPT-11 enzyme/prodrug therapy in transgenic mouse model of intracerebellar medulloblastoma. Gene Ther 20 : 143-50.

29. Peirce CB, Cone WV, et al. (1949) Medulloblastoma; non-operative management with roentgen therapy after aspiration biopsy. Radiology 52 621-32.

30. Li L, Story M, Legerski RJ (2001) Cellular responses to ionizing radiation damage. Int J Radiat Oncol Biol Phys 49: 1157-62.

31. Silverman CL, Palkes H, Talent B, Kovnar E, et al. (1984) Late effects of radiotherapy on patients with cerebellar medulloblastoma. Cancer 54: 825-9.

32. Brodin NP, Vogelius IR, Maraldo MV, Munck af Rosenschöld P, Aznar MC, e al. (2012) Life years lost--comparing potentially fatal late complications afte radiotherapy for pediatric medulloblastoma on a common scale. Cancer 118 : 5432-40.

33. Vaupel $P$ (2004) Tumor microenvironmental physiology and its implications for radiation oncology. Semin Radiat Oncol 14: 198-206.

34. Nagaraju GP, Nalla AK, Gupta R, Mohanam S, Gujrati M, et al. (2011) siRNAmediated downregulation of MMP-9 and UPAR in combination with radiation induces G2/M cell-cycle arrest in Medulloblastoma. Mol Cancer Res 9: 51-66.

35. Kotipatruni RR, Nalla AK, Asuthkar S, Gondi CS, Dinh DH, et al. (2012) Apoptosis induced by knockdown of UPAR and MMP-9 is mediated by inactivation of EGFR/STAT3 signaling in medulloblastoma. PLoS One 7 : e44798.

36. Bhoopathi P, Chetty C, Gujrati M, Dinh DH, Rao JS, et al. (2010) Cathepsin B facilitates autophagy-mediated apoptosis in SPARC overexpressed primitive neuroectodermal tumor cells. Cell Death Differ 17: 1529-39.

37. Chetty C, Dontula R, Ganji PN, Gujrati M, Lakka SS (2012) SPARC expression induces cell cycle arrest via STAT3 signaling pathway in medulloblastoma cells. Biochem Biophys Res Commun 417: 874-9.

38 Chetty C, Dontula R, Gujrati M, Dinh DH, Lakka SS (2012) Blockade of SOX4 mediated DNA repair by SPARC enhances radioresponse in medulloblastoma. Cancer Lett 323: 188-98.

39. Whiteway SL, Harris PS, Venkataraman S, Alimova I, Birks DK, et al. (2013) Inhibition of cyclin-dependent kinase 6 suppresses cell proliferation and enhances radiation sensitivity in medulloblastoma cells. J Neurooncol 111 113-21.

40. Hutzen B, Pierson CR, Russell SJ, Galanis E, Raffel C, et al. (2012) Treatment of medulloblastoma using an oncolytic measles virus encoding the thyroidal sodium iodide symporter shows enhanced efficacy with radioiodine. BMC Cancer 12: 508

41. Chen K, Rajewsky N (2007) The evolution of gene regulation by transcription factors and microRNAs. Nat Rev Genet 8: 93-103.

42. Bartel DP (2009) MicroRNAs: target recognition and regulatory functions. Cell 136: $215-33$

43. Tong AW, Nemunaitis J (2008) Modulation of miRNA activity in human cancer: a new paradigm for cancer gene therapy? Cancer Gene Ther 15 341-55.

44. Jay C, Nemunaitis J, Chen P, Fulgham P, Tong AW, et al. (2007) miRNA profiling for diagnosis and prognosis of human cancer. DNA Cell Biol 26: 293300

45. Pierson J, Hostager B, Fan R, Vibhakar R (2008) Regulation of cyclin dependent kinase 6 by microRNA 124 in medulloblastoma. J Neurooncol 90: 1-7.

46. Venkataraman S, Alimova I, Fan R, Harris P, Foreman N, et al. (2010) MicroRNA 128a increases intracellular ROS level by targeting Bmi-1 and inhibits medulloblastoma cancer cell growth by promoting senescence. PLoS One 5: e10748.

47. Silber J, Hashizume R, Felix T, Hariono S, Yu M, et al. (2013) Expression of miR-124 inhibits growth of medulloblastoma cells. Neuro Oncol 15: 83-90.

48. Garzia L, Andolfo I, Cusanelli E, Marino N, Petrosino G, et al. (2009) MicroRNA-199b-5p impairs cancer stem cells through negative regulation of HES1 in medulloblastoma. PLoS One 4: e4998.

49. Ferretti E, De Smaele E, Miele E, Laneve P, Po A, et al. (2008) Concerted microRNA control of Hedgehog signalling in cerebellar neuronal progenitor and tumour cells. EMBO J 27: 2616-27.

50. Li KK, Pang JC, Lau KM, Zhou L, Mao Y, et al. (2013) MiR-383 is Downregulated in Medulloblastoma and Targets Peroxiredoxin 3 (PRDX3). Brain Pathol 23: 413-25.

51. Li KK, Pang JC, Ching AK, Wong CK, Kong X, et al. (2009) miR-124 is frequently down-regulated in medulloblastoma and is a negative regulator of SLC16A1. Hum Pathol 40: 1234-43.

52. de Antonellis P, Medaglia C, Cusanelli E, Andolfo I, Liguori L, et al. (2011) MiR-34a targeting of Notch ligand delta-like 1 impairs CD15+/CD133+ tumorpropagating cells and supports neural differentiation in medulloblastoma. PLoS One 6: e24584.

53. Ishibashi M, Moriyoshi K, Sasai Y, Shiota K, Nakanishi S, et al. (1994) Persistent expression of helix-loop-helix factor HES-1 prevents mammalian neural differentiation in the central nervous system. EMBO J 13: 1799-805.

54. Weeraratne SD, Amani V, Neiss A, Teider N, Scott DK, et al. (2011) miR$34 \mathrm{a}$ confers chemosensitivity through modulation of MAGE-A and p53 in medulloblastoma. Neuro Oncol 13: 165-75.

55. Ferretti E, De Smaele E, Po A, Di Marcotullio L, Tosi E, et al. (2009) MicroRNA profiling in human medulloblastoma. Int J Cancer 124: 568-77.

56. Venkataraman S, Birks DK, Balakrishnan I, Alimova I, Harris PS, et al. (2013) MicroRNA 218 acts as a tumor suppressor by targeting multiple cance phenotype-associated genes in medulloblastoma. J Biol Chem 288: 1918-28.

57. Hallahan AR, Pritchard JI, Hansen S, Benson M, Stoeck J, et al. (2004) The SmoA1 mouse model reveals that notch signaling is critical for the growth and survival of sonic hedgehog-induced medulloblastomas. Cancer Res 64 $7794-800$

58. Stanford MM, McFadden G (2007) Myxoma virus and oncolytic virotherapy: a new biologic weapon in the war against cancer. Expert Opin Biol Ther 7: $1415-25$

59. Lim KJ, Pang JC, Lau KM, Zhou L, Mao Y, et al. (2011) A polymeric nanoparticle formulation of curcumin inhibits growth, clonogenicity and stemlike fraction in malignant brain tumors. Cancer Biol Ther 11: 464-73.

60. Chenna V, Hu C, Pramanik D, Aftab BT, Karikari C, et al. (2012) A polymeric nanoparticle encapsulated small-molecule inhibitor of Hedgehog signaling $(\mathrm{NanoHHI})$ bypasses secondary mutational resistance to Smoothened antagonists. Mol Cancer Ther 11: 165-73.

61. Tobey MacDonald (2012) The application of nanoparticle liposome-impramine blue in the treatment of medulloblastoma in the SmoA1 transgenic mice. Neuro Oncol 14 (suppl 1): i82-i105. 